\title{
Editorial
}

\section{Carbonaceous Particles in the Atmosphere: Experimental and Modelling Issues}

\author{
Giulia Pavese, ${ }^{1}$ Lucas Alados-Arboledas, ${ }^{2}$ Junji Cao, ${ }^{3}$ and S. K. Satheesh ${ }^{4}$ \\ ${ }^{1}$ Institute of Methodologies for Environmental Analysis, National Council of Research (CNR-IMAA), \\ Contrada S. Loja, 85050 Tito Scalo, Italy \\ ${ }^{2}$ Centro Andaluz de Medio Ambiente, University of Granada, 18071 Granada, Spain \\ ${ }^{3}$ Key Laboratory of Aerosol, SKLLQG, Institute of Earth Environment, Chinese Academy of Sciences, Xian 710075, China \\ ${ }^{4}$ Centre for Atmospheric and Oceanic Sciences, Indian Institute of Science, Bangalore 560012, India
}

Correspondence should be addressed to Giulia Pavese; pavese@imaa.cnr.it

Received 11 May 2014; Accepted 11 May 2014; Published 26 May 2014

Copyright (C) 2014 Giulia Pavese et al. This is an open access article distributed under the Creative Commons Attribution License, which permits unrestricted use, distribution, and reproduction in any medium, provided the original work is properly cited.

Carbonaceous particles and their organic component are one of the major combustion by-products and they are recognized to play a relevant role in radiative transfer, air quality, and human health, due to their fine-submicrometric nature. These effects are magnified by transboundary air masses transport of natural fires plumes or anthropogenic emissions from domestic heating and industrial activities, affecting not only the source areas. In fact, analysis on snow samples from different arctic sites revealed the presence of carbonaceous particulate matter, with biomass burning identified as responsible for more than $90 \%$ of these particles. As a consequence of this deposition, snow albedo variations are added to the other factors influencing Earth's radiative budget.

For these reasons, there is a growing interest toward the above-mentioned arguments, but there is also a need to assess the role of carbonaceous particles [1] and to review the different measurements techniques, highlighting their limitations and uncertainties [2].

The papers included in this special issue improve the comprehension of processes involving carbonaceous particles considering them under different points of view because both experimental and modeling approaches are examined.

S. Byčenkienè et al., starting from one-year continuous aethalometer measurements of black carbon (BC) content at a background site in Lithuania, were able to study the transport of different air masses. In particular, air masses from Ukraine and the volcanic plume from the Grimsvotn eruption were characterized by estimating the alpha absorption parameter at shorter and longer wavelengths. In this way, they demonstrate that grass burning was the major source of carbonaceous particles in the atmosphere. Moreover, new secondary particle formation from volcanic gas emissions, occurred within the lower troposphere, was detected even at a large distance from the eruption site.

Y. Aboel Fetouh et al. use long-term series of parameters from the Tropospheric Emission Spectrometer (TES) on board the Aura satellite to assess the dominant component below the inversion layer. Time series analysis, autocorrelations, and cross correlations were useful to understand the connections between those parameters and their local effect. In particular, they were able to identify different pollution episodes known as Black Clouds over Cairo city and their climatic origin, confirming biomass burning to be a serious problem affecting air quality in that area.

J. L. Hand et al. aggregated OC and EC data from 2007 to 2010 at over 300 sites from the rural/remote IMPROVE (interagency monitoring of protected visual environments) network and the Environmental Protection Agency's urban chemical speciation network to characterize the spatial and seasonal patterns in rural and urban carbonaceous aerosols. From the interpolation of these data, they found large spatial patterns from which local and regional impacts of carbonaceous aerosols across the United States were inferred. 
In particular, they found urban impact the highest and more localized in the West in winter. Eastern particulate organic matter $(\mathrm{POM})$ concentrations were the highest in the Southeast in spring, during prescribed fires, and were more regional during summer with a major influence of secondary sources.

M. Ruppel et al. compared sedimentary measurements of spheroidal carbonaceous particles (SCP), obtained from lake sediments in Northern Europe from 1850 to 2010, to model data from the chemistry transport model OsloCTM2. To determine the origin of SCPs, they generated back trajectories of air masses to the study sites. In general, they found a good agreement between trends of SCP deposition and modelled results but, on a smaller geographical scale, they highlighted the lack of detailed information on air mass transport patterns in the model, suggesting the need for numerous observational records to reliably validate model results.

J. Y. Lee and L. M. Hildemann studied the hygroscopic behavior at $12^{\circ} \mathrm{C}$ over aqueous bulk solutions containing dicarboxylic acids (malonic, glutaric, and succinic). They compared their results to Peng's modified UNIFAC model results. They observed systematic differences between measured and modelled hygroscopic behavior for mixtures of dicarboxylic acids couples, over a range of concentrations. These results suggest considering interactions between different organic components in order to accurately model aerosol hygroscopicity and, for this reason, further measurements are strongly requested.

A. Singh et al. measured the mass concentrations of both black carbon (BC) and elemental carbon (EC) in the IndoGangetic Plain (IGP), using both optical and thermooptical techniques, with the objective to assess the characteristics of $\mathrm{BC}$ and $\mathrm{EC}$ from various kinds of biomass burning emissions. They observed $\mathrm{BC} / \mathrm{EC}$ ratios greater than 1.0 during paddy-residue burning emissions associated with high mass concentrations of EC, OC, and OC/EC ratio and estimated the value of the Angström exponent $(\alpha)$, derived from aethalometer data, that is, approximately 1.5 , for the postharvest agricultural-waste burning emissions. This value was so far unknown for the IGP.

Giulia Pavese

Lucas Alados-Arboledas

Junji Cao

S. K. Satheesh

\section{References}

[1] T. C. Bond, S. J. Doherty, and D. W. Fahey, "Bounding the role of black carbon in the climate system: a scientific assessment," Journal of Geophysical Research: Atmosphere, vol. 118, pp. 53805552, 2013.

[2] D. A. Lack, H. Moosmüller, G. R. McMeeking, R. K. Chakrabarty, and D. Baumgardner, "Characterizing elemental, equivalent black, and refractory black carbon aerosol particles: a review of techniques, their limitations and uncertainties," Analytical and Bioanalytical Chemistry, vol. 406, pp. 99-122, 2014. 

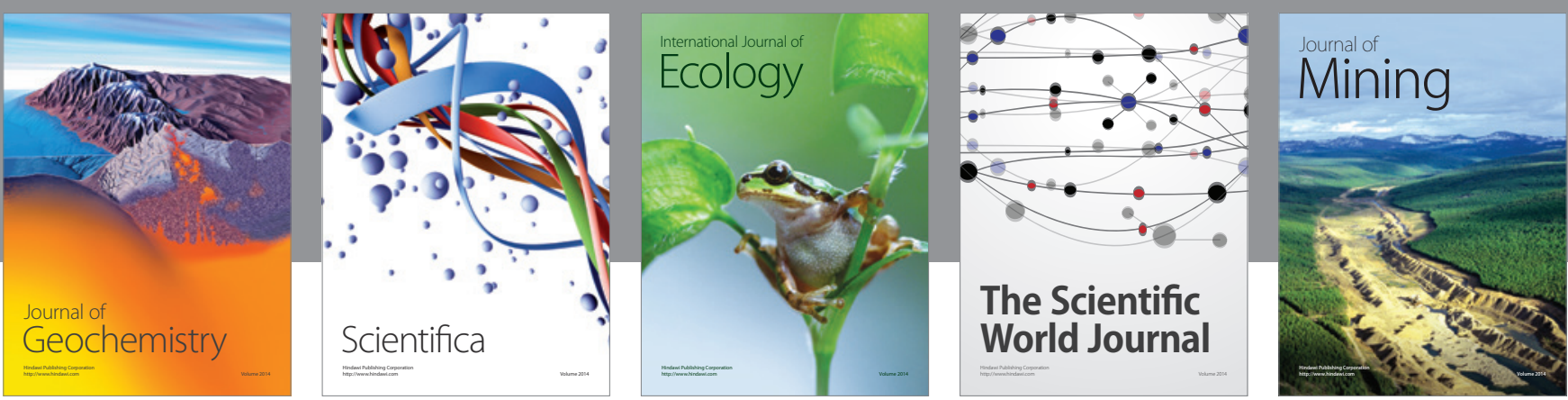

The Scientific World Journal
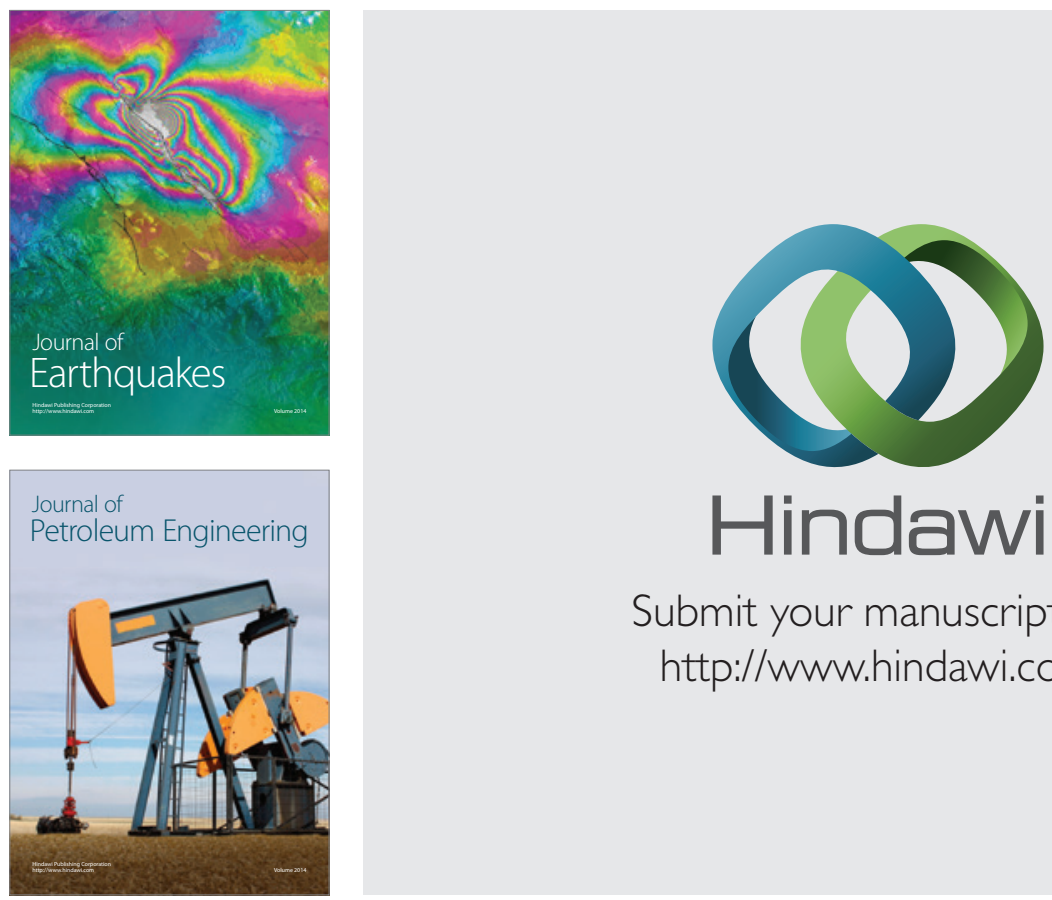

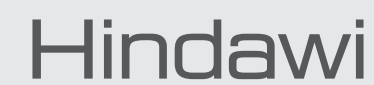

Submit your manuscripts at

http://www.hindawi.com
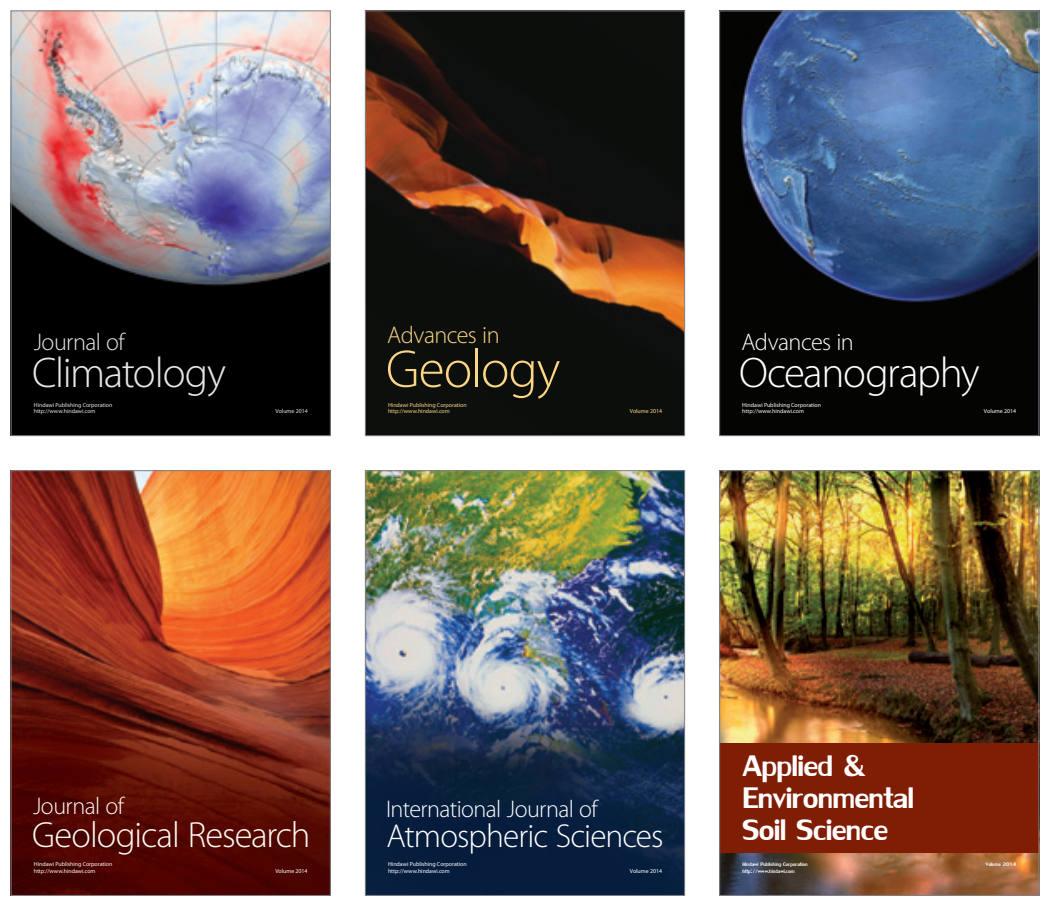
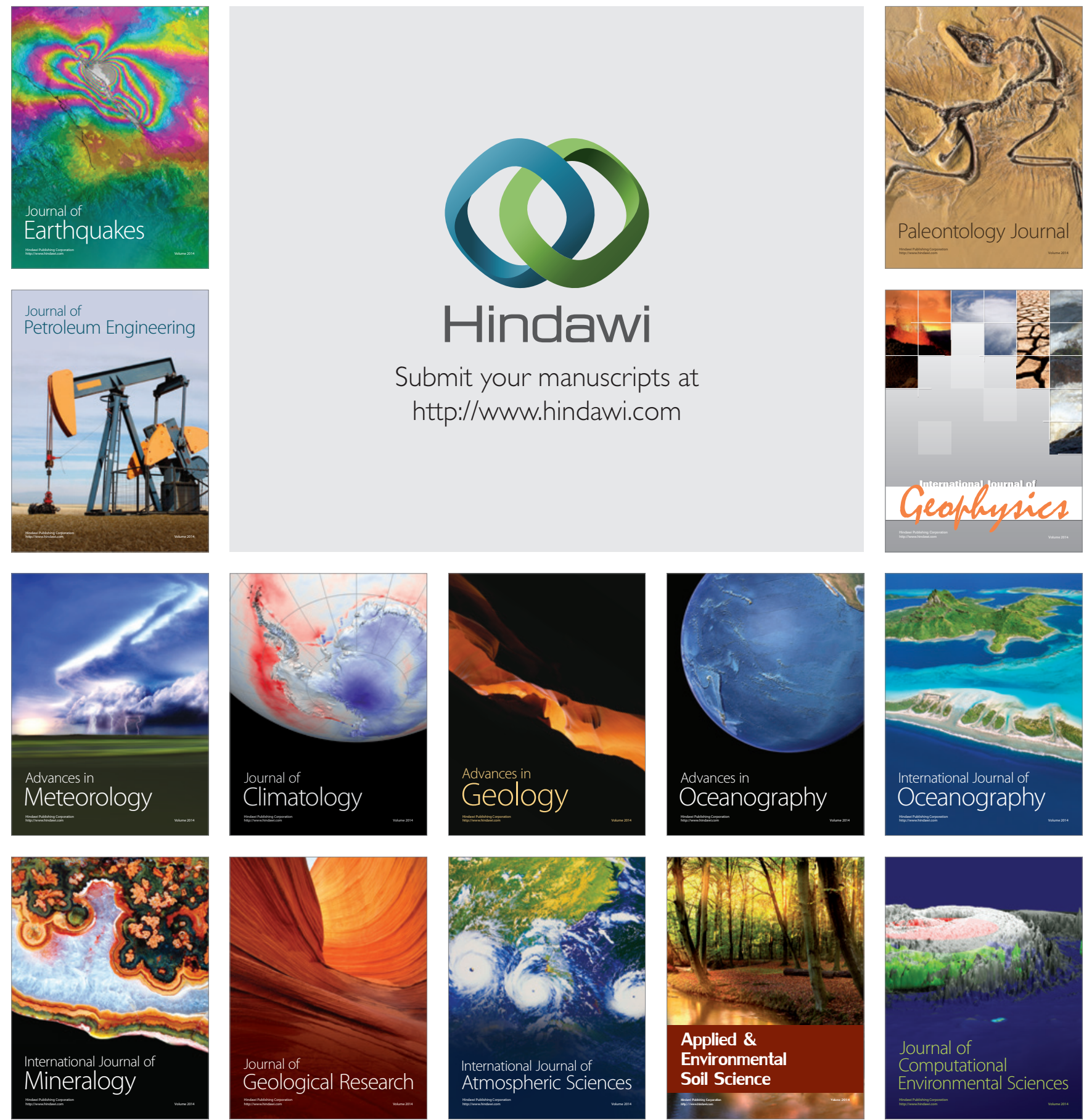